\title{
Correction to: Feature shape complexity: a new criterion for the simplification of feature-based 3D CAD models
}

\section{Soonjo Kwon ${ }^{1} \cdot$ Duhwan Mun ${ }^{2} \cdot$ Byung Chul Kim ${ }^{3} \cdot$ Soonhung Han ${ }^{1}$}

Published online: 17 May 2019

(C) Springer-Verlag London Ltd., part of Springer Nature 2019

\section{Correction to: Int J Adv Manuf Technol \\ https://doi.org/10.1007/s00170-016-8937-1}

In the original publication, the surface complexity $\left(C_{S}^{i}\right)$ of $F_{1}$ presented in Fig. 4 was incorrectly calculated. The correct image of Fig. 4 is given below and the correct explanation in the paragraph for Fig. 4 is also presented below.

The online version of the original article can be found at https://doi.org/ $10.1007 / \mathrm{s} 00170-016-8937-1$

Soonhung Han

shhan@kaist.ac.kr

1 Department of Mechanical Engineering, Graduate School of Ocean Systems Engineering, Korea Advanced Institute of Science and Technology, 291 Daehak-ro, Yuseong-gu, Daejeon 305-701, South Korea

2 Department of Precision Mechanical Engineering, Kyungpook National University, 2559, Gyeongsang-daero,

Sangju, Gyeongsangbuk-do 742-711, South Korea

3 Department of Mechanical Engineering, Dong-A University, 37, Nakdong-daero 550beon-gil, Saha-gu, Busan 604-714, South Korea 
Fig. 4 Element complexities of two similar features
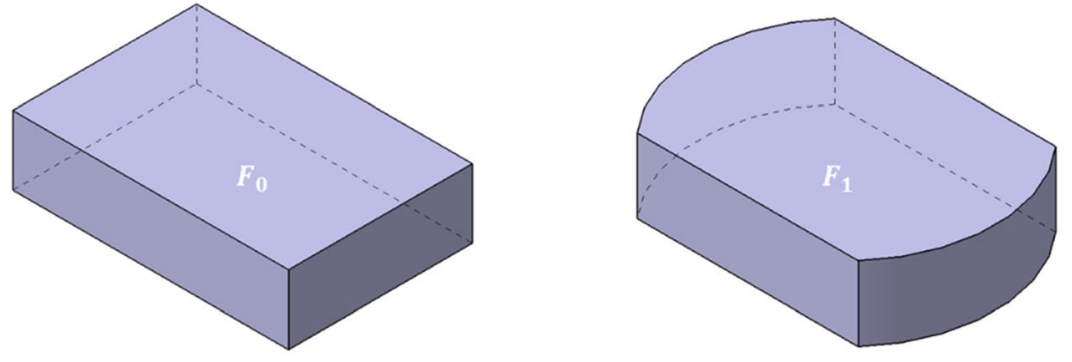

\begin{tabular}{cccc}
\hline Feature & Surface complexity $\left(C_{S}^{i}\right)$ & Curve complexity $\left(C_{C}^{i}\right)$ & Element complexity $\left(\boldsymbol{C E}^{\boldsymbol{i}}\right)$ \\
\hline$F_{0}$ & $6 \times U($ Plane $)=36$ & $12 \times U($ Straight Line $)=72$ & $\mathbf{1 0 8 / 1 2 6 = \mathbf { 0 . 8 5 7 }}$ \\
\hline$F_{1}$ & $\begin{array}{c}4 \times U(\text { Plane }) \\
+2 \times U(\text { Cylinder })=38\end{array}$ & $\begin{array}{l}8 \times U(\text { Straight Line }) \\
+4 \times U(\text { Circle })=88\end{array}$ & $\mathbf{1 2 6 / 1 2 6 = 1}$ \\
\hline
\end{tabular}

In the 5th paragraph of the sub clause ' 3.2 Element complexity', the correct explanation for Fig. 4 is presented below.

"Figure 4 shows a comparison of the $C E^{i}$ of two hexahedral features. $F_{0}$ consists of six planes and 12 straight lines, and $F_{1}$ consists of four planes, two cylindrical surfaces, eight straight lines, and four arcs. Therefore, $F_{0}$ has a smaller $C E^{i}$ than $F_{1}$. Suppose these features have the same volume. Then, the FSC of the features will be $F S C^{0}=(1 / 0.857)(1+0.857)=2.167$ and $F S C^{1}=(1 / 1)(1+1)=2$ (i.e., $\left.F S C^{0}>F S C^{1}\right)$. Hence, $F_{1}$ will be removed first, because a feature with a higher $C E^{i}$ affects the data size of the original model to a greater extent. The introduction of FSC is closely related to the main purpose of research on simplification, where the aim is to preserve the outer shape of the original model and minimize the data size simultaneously."

Publisher's note Springer Nature remains neutral with regard to jurisdictional claims in published maps and institutional affiliations. 